\title{
Manganese encephalopathy: utility of early magnetic resonance imaging
}

\author{
Kevin Nelson, Jan Golnick, Thomas Korn, Carol Angle
}

\begin{abstract}
The use of magnetic resonance imaging (MRI) provides visual evidence of cerebral deposits of paramagnetic metals. The usefulness of MRI is described in connection with the manganese poisoning of a 44 year old arc welder who had been engaged in the repair and recycling of railroad track made of manganese steel alloy.
\end{abstract}

(British fournal of Industrial Medicine 1993;50:510-513)

The diagnosis of manganese $(\mathrm{Mn})$ poisoning in industrial workers is not usually made until the development of symptoms and irreversible brain damage. Concentrations of $\mathrm{Mn}$ in blood and urine reflect the rapid clearance of absorbed $\mathrm{Mn}$ and are insensitive and non-specific in both prediction and diagnosis. In magnetic resonance imaging (MRI) the paramagnetic qualities of $\mathrm{Mn}$ and related metals such as iron and copper are responsible for shortening of the $T_{1}$ relaxation time and an acute increase in signal intensity. Experimental $\mathrm{Mn}$ poisoning of the primate and the $\mathrm{Mn}$ overload of prolonged total parenteral nutrition produce symmetrical hyperintense signals in the basal ganglia, mid brain, and pons. ${ }^{1-3}$ Resolution of this signal, usually within six months, reflects the rapid clearance of $\mathrm{Mn}$ from the brain despite permanent neurological damage. The potential, although transient, utility of MRI in the diagnosis of industrial $\mathrm{Mn}$ poisoning is evident from the case discussed.

Department of Radiology, Bishop Clarkson Memorial Hospital, Omaha, Nebraska, USA $\mathrm{K}$ Nelson

Midlands Neurological and Headache Center, Papillion, Nebraska, USA

J Golnick

Psychology Laboratories, Lincoln, Nebraska, USA

T Korn

Department of Pediatrics, University of Nebraska Medical Center, Omaha, Nebraska, USA

C Angle

\section{Case report}

The patient was a 44 year old man who had been an arc welder for 25 years, responsible for repair and recycling of railroad track made of $\mathrm{Mn}$-steel alloy $(11 \%-14 \% \mathrm{Mn})$. For 15 years he had worked indoors with no local exhaust. His tasks involved the use of welding rods of $\mathrm{Mn}$-steel alloy and hot carbon cutting of castings of a $20 \% \mathrm{Mn}$ alloy. In his 23rd year of employment he developed progressively severe headache and irritability. By year 24 he was drinking more alcohol and this was thought to be the reason why he was short tempered and verbally abusive. After stopping drinking alcohol he was less irritable but more easily tearful. $\mathrm{He}$ had insomnia and lassitude with no interest in his usual activities. In year 25 he developed progressive confusion, poor memory, impaired cognition, and paranoid thoughts. His right leg began to give way precipitously so that he often fell and he had difficulty stopping when walking down a slope. His speech was intermittently slurred and he substituted unusual words. Paper work, calculations, and balancing a cheque book became difficult. He became lost on the way to work, was clumsy with small tools, and could not remember well known techniques such as knotting his tie. Increased sweating with a strong metallic odour and sialorrhea were noted. He had no symptoms of metal fume fever or pneumonia.

The neurological findings at the termination of his job included a right hemisensory deficit, weakness of the right arm and leg, and hyperreflexia of the lower extremities. Computed tomography, electroencephalogram, electromyogram, and blood chemistry including folate, $\mathbf{B}_{12}$, glucose, and copper concentrations, and thyroid function were all within the normal range. Cardiopulmonary evaluation was unremarkable. MRI with a spin echo technique showed hyperintense signals due to a shortened $T_{1}$ relaxation time in the basal ganglia and midbrain (fig 1 top). The $T_{2}$ signals were unremarkable (fig 1 bottom).

Repeat MRI six months after stopping work (fig 2) showed almost complete resolution of the high intensity signals in the midbrain. A single photon emission computed tomography scan showed 

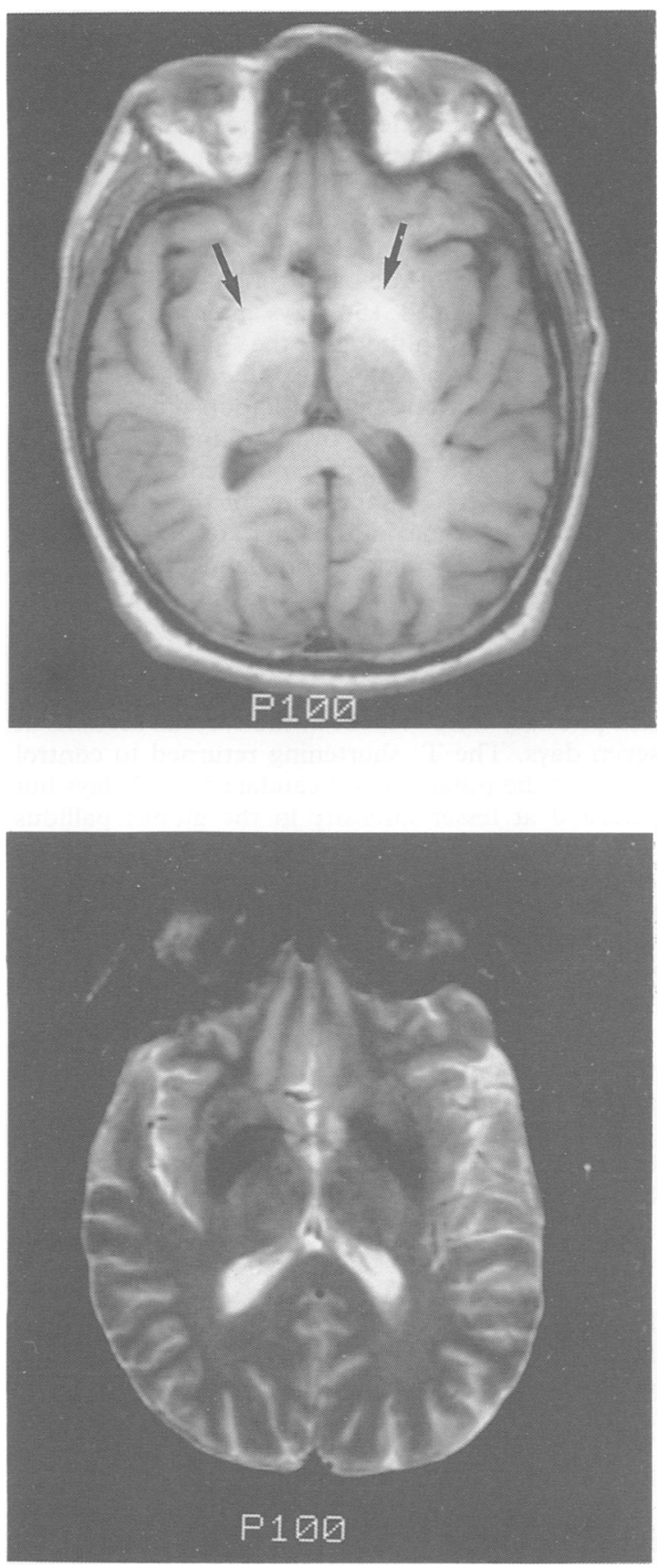

Figure 1 Initial MRI. Top; axial T1 weighted image (TR/TE, 500/15 ms) at the level of the basal ganglia. Increased signal intensity in the globus pallidus (arrows) that is bilateral and symmetrical reflects shortened $T 1$ relaxation due the paramagnetic effect of Mn. Bottom; T2 weighted image (TR/TE, 2500/70 ms) is unremarkable. Some decreased signal intensity in the basal ganglia is normally expected for this age of patient.

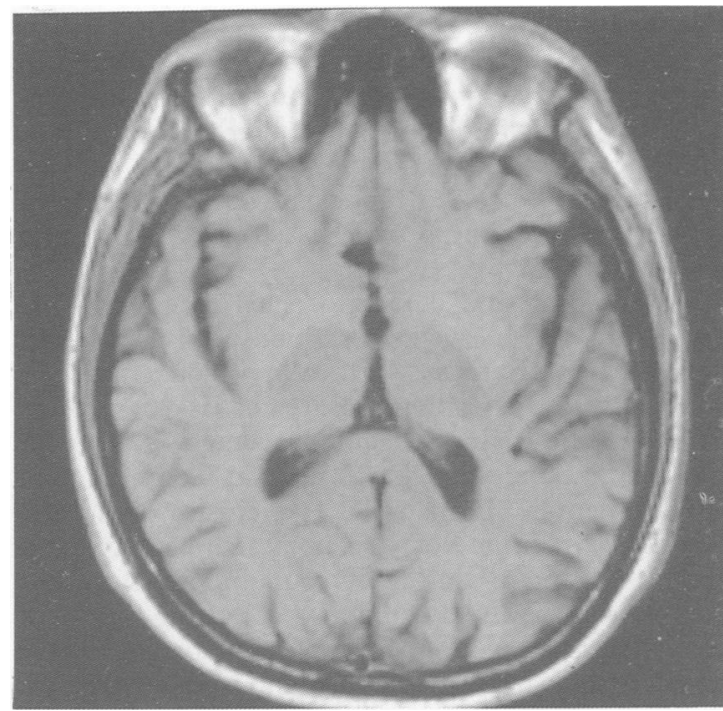

Figure 2 Six month follow up MRI. Axial T1 weighted image (TR/TE, 750/15 ms) at the same level as fig 1 is normal. The increased signal intensity has resolved secondary to the decreased concentration of $\mathrm{Mn}$ after physiological excretion.

decreased uptake over the entire cortex with localised decreases in the basal ganglia.

Neuropsychiatric testing eight months after he stopped work showed decreased hand grips, impaired vigilance, recall, rate of learning, amnestic processing, and perceptual and sequencing abilities with conceptual concreteness, dysarthric speech, dyscalculia, and graphic constructional dysfunction.

At ten months after termination there was no improvement in neuropsychiatric state. He required some assistance in daily living because he might fall in the shower, was too clumsy to button his clothing, and too forgetful to function independently. He could shop if given a list but could not calculate the correct change. A positron emission scan showed a generalised decrease in glucose uptake with no localised decreases in the basal ganglia or pons.

His blood $\mathrm{Mn}$ concentration was $0.018 \mu \mathrm{M}$ $(1.0 \mu \mathrm{g}) / \mathrm{kg}$ (normal $0.006-0.015 \mu \mathrm{M})$. Urinary $\mathrm{Mn}$ concentration obtained after treatment with $2 \mathrm{~g}$ EDTA IV was $0.31 \mu \mathrm{M} /$ day $(17 \mu \mathrm{g} /$ day) (normal $<0.005 \mu \mathrm{M}(0.3 \mu \mathrm{g}) /$ day $)$. There was no increase in urinary copper, cadmium, mercury, or lead concentrations. A cloth sample from one of his fire resistant welder's shirts worn at work for two days contained $182 \mathrm{mM}(9972 \mathrm{mg}) \mathrm{Mn} / \mathrm{kg}$ and $66 \mathrm{mM}$ $(3700 \mathrm{mg}$ ) iron $/ \mathrm{kg}$. A control shirt, worn at home for two days contained $2.3 \mathrm{mM}(128 \mathrm{mg}) \mathrm{Mn} \mathrm{kg}$ and $0.3 \mathrm{mM}(17 \cdot 2 \mathrm{mg})$ iron $/ \mathrm{kg}$. 


\section{Discussion}

Manganese encephalopathy seemed established in this man by the cinical syndrome of Parkinsonianlike dementia with exclusion of alternate diagnoses, the long term occupational exposure, the unusual persistence of a raised blood and urinary Mn concentration 10 months after he stopped work, and serial MRI.

Arc welding and cutting of steel containing 11$14 \% \mathrm{Mn}$ is a well described cause of $\mathrm{Mn}$ poisoning. ${ }^{45}$ Fumes with $\mathrm{Mn}$ concentrations $<5 \mathrm{mg} / \mathrm{m}^{3}$ are considered a greater risk than dust. The eight hour time weighted average (TWA) for $\mathrm{Mn}$ recommended by the American Conference of Governmental Industrial Hygienists and the National Institute of Occupational Safety and Health is $1 \mathrm{mg} / \mathrm{m}^{3}$ and the Occupational Safety and Health Act TWA is $5 \mathrm{mg} / \mathrm{m} .{ }^{36}$ The deposition of more $\mathrm{Mn}$ than iron on the subject's work shirt may relate to the greater volatility and smaller particle size of the $\mathrm{Mn}$ in the metals released from the alloy.

Blood Mn has a half life of 10-42 days ${ }^{7}$ and is of little assistance in the clinical diagnosis; $\mathrm{Mn}$ is excreted predominately in the faeces and accumulates in liver disease. Urinary $\mathbf{M n}$ declines at the same rate as blood Mn. Assuming a half life of 40 days, a urinary $\mathrm{Mn}$ concentration of $0.31 \mu \mathrm{M}$ $(17 \mu \mathrm{g}) /$ day after EDTA treatment would predict a urinary $\mathrm{Mn}$ concentration as high as $42 \mu \mathrm{M}$ $(2304 \mu \mathrm{g}) /$ day 10 months earlier.

In MRI, paramagnetic ions such as Mn, gadolinium, copper, and iron can cause alterations in signal intensity due principally to their large magnetic moments. The $\mathrm{Mn}$ ion $\left(\mathrm{Mn}^{2+}\right)$ has five unpaired electrons in the $3 \mathrm{~d}$ orbit, which results in its large magnetic moment. In clinical MRI, manganese promotes $T_{1}$ relaxation in the external magnetic field that has been perturbed by an RF pulse. The resultant shortened $T_{1}$ relaxation time increases the signal intensity from the tissue being imaged on a $T_{1}$ weighted MR pulse sequence which uses short pulse repetition times (TR) and echo times (TE). Therefore $T_{1}$ weighted MRI can provide evidence of deposition of $\mathrm{Mn}$ in the brain, which physiologically occurs in the globus pallidus of the basal ganglia. This is visualised as abnormally increased signal intensity in the globus pallidus on $T_{1}$ weighted images compared with normal surrounding brain.

The effect of a paramagnetic ion such as $\mathrm{Mn}$ on $T_{1}$ relaxation is concentration dependent and biphasic. Signal intensity on $T_{1}$ weighted images progressively increases in relation to increasing concentrations of a paramagnetic species to a critical point at which time $T_{2}$ effects predominate and result in signal loss on the $T_{1}$ weighted image. The concentration of $\mathrm{Mn}$ necessary to cause signal loss in the globus pallidus of the human brain on a $T_{1}$ weighted image is not known but is most likely incompatible with life.

The MRI provides visual evidence of cerebral deposits of paramagnetic metals resulting from prolonged total parenteral nutrition in subjects with and without symptoms of $\mathrm{Mn}$ neurotoxicity. ${ }^{12}$ In the total parenteral nutrition recipient reported by Ejima et $a l,{ }^{1}$ the high intensity signal of the $T_{1}$ weighted images of the basal ganglia and brainstem were much reduced 154 days after discontinuing parenteral $\mathrm{Mn}$ although the globus pallidus retained some hyperintensity. There was a simultaneous decrease in the signs of Parkinsonism.

Experimental studies by Newland et al, ${ }^{3}$ after administration of inhaled or intravenous $\mathrm{MnCl}_{2}$ to the monkey defined shortening of the $T_{1}$ spin lattice relaxation time in the caudate and lenticular nuclei, substantia nigra, subthalamic area, ventromedial hypothalamus, and the pituitary. Striata were visible on horizontal sections at two days after $0.18 \mathrm{mM}(10 \mathrm{mg}) \mathrm{Mn} / \mathrm{kg}$ but much more intense highlighting of the substantia nigra, basal ganglia, and pituitary were evident in the coronal sections at seven days. The $T_{1}$ shortening returned to control values in the putamen and caudate by 182 days but persisted at lesser intensity in the globus pallidus and pituitary. Inhalation of $\mathrm{Mn}$ evoked a similar regional distribution but with variation in the magnitude, time of onset, and duration. After inhalation, $\mathrm{Mn}$ is deposited in the lung and is slowly released long after the exposure has terminated. This may explain the prolonged increase in urinary Mn concentration in the subject reported here and the delayed onset of symptoms as long as six years after retirement in workers reported by Sano et al. ${ }^{8}$

In subjects without documented exposure to $\mathrm{Mn}$ other causes of increased $T_{1}$ signal intensity in the basal ganglia must be considered. There is a similar signal due to iron deposition in Hallervarden Spitz disease and to copper in Wilson's disease. ${ }^{910} \mathrm{~A}$ shortened $T_{1}$ relaxation time due to fat, haemoglobin breakdown products, melanoma, neurofibromatosis, and calcification is usually asymmetric and often associated with oedema or a mass effect. Fat is also characterised by similar abnormalities in the $T_{2}$ weighted image ${ }^{9}$ and was excluded in this case by fat suppression MRI scanning.

The prodromal symptoms of asthenia, anorexia, myalgia, irritability, labile affect and uncontrolled violence, insomnia, and decreased libido are non specific. ${ }^{711}$ The intermediate stage is more characteristic: inappropriate laughing or crying, clumsiness, increased tendon reflexes in the legs, speech disorders, mask-like face, sialorrhea, and increased sweat with a metallic odour. The late findings are relatively diagnostic although the mask-like face, slow shuffling gait without arm movement, and bent trunk resemble Parkinsonism: additional find- 
ings include the inability to stop walking while going downhill or to protect against a backward push, small amplitude tremors that increase on movement, weakness, stiffness, and impaired speech. Hua and Huang were unable to define neurobehavioural deficits other than a mild decrease in response speed in 17 exposed workers without Parkinsonian or other overt neurological changes. ${ }^{12}$

Given the inadequacy of blood and urinary $\mathbf{M n}$ concentrations as biological indices of exposure and the non-specific neurological and cognitive dysfunction, MRI may prove useful in the presymptomatic or prodromal detection of $\mathrm{Mn}$ toxicity. Of nine patients on total parenteral nutrition with symmetrical hyperintense $T_{1}$ weighted images of the globus pallidus, only five had neurological symptoms. ${ }^{9}$ Early diagnosis is essential as the established symptoms of $\mathrm{Mn}$ intoxication do not usually regress after termination of exposure ${ }^{7113-15}$ or clearance of $\mathrm{Mn}$ from the brain as determined analytically or by MRI. ${ }^{1313}$ Thus MRI should be considered as an important adjunct to air monitoring and to blood and urinary concentrations of $\mathrm{Mn}$ for the evaluation and diagnosis of $\mathrm{Mn}$ poisoning in workers at risk.

Requests for reprints to: Carol $\mathrm{R}$ Angle, $\mathrm{MD}$, Department of Pediatrics, University of Nebraska Medical Center, 600 South 42nd Street, Omaha, NE 68198/6055, USA.
1 Ejima A, Imamura T, Nakamura S, et al. Manganese intoxication during total parenteral nutrition. Lancet 1992;339:426

2 Mirowitz SA, Westrich TJ, Hirsch JD. Hyperintense basal ganglia on T1-weighted MR images in patients receiving parenteral nutrition. Radiology 1991;181:117-20.

3 Newland MC, Cox C, Hamada R, Oberdoerster G, Weiss B. The clearance of manganese chloride in the primate. Fundam Appl Toxicol 1987;9:314-28.

4 Tanaka S, Lieben J. Manganese poisoning and exposure in Pennsylvania. Arch Environ Health 1969;19:674-84.

5 Whitlock CM, Amuso SJ, Bittenbender JB. Chronic neurological disease in two manganese steel workers. Am Ind Hyg Assoc f 1966;27:454-9.

6 American Conference of Governmental Industrial Hygienists, Inc. Documentation of the threshold limit values and biological exposure indices, 5th ed Cincinnati, OH: 1986:354-5.

7 Mena I, Marin O, Fuenzalida S, Cotzias GC. Chronic manganese poisoning-clinical picture and manganese turnover. Neurology 1967;17128-36.

8 Sano S, Yamashita N, Kawanishi S, et al. An epidemiologic survey and clinical investigations on retired workers from manganese mines and ore grinders in the Kyoto prefectore. Fapanese Fournal of Hygiene 1982;37:566-79.

9 Markesberry WR, Ehmann WD, Hossain T, Alauddin M. Brain manganese concentrations in human and Alzheimer's disease. Neurotoxicology 1984;5:49-58.

10 Barbeau A. Manganese and extrapyramidal disorders. Neurotoxicology 1984;5:13-36.

11 Rodier J. Manganese poisoning in Moroccan mines. $\mathrm{Br} \mathcal{F}$ Ind Med 1955;12:21-35.

12 Hua MS, Huang CC. Chronic occupational exposure to manganese and neurobehavioral function. $f$ Clin Exp Neuropsychol 1991;13:495-507.

13 Cotzias GC, Horiuchi MS, Fuenzalida S, Mena I. Clearance of tissue manganese concentrations with persistence of the neurologic picture. Neurology 1968;18:376-82.

14 Huang CC, Chu NS, Lu CS, et al Chronic manganese intoxication. Arch Neurol 1989;46:1104-6.

15 Yamada M, Ohno S, Okayasu I, et al Chronic manganese poisoning: a neuropathological study with determination of manganese distribution in the brain. Acta Neuropatho 1986;70:273-8.

Accepted 7 September 1992 